\title{
THE PROPER AFFILIATION OF PSYCHOLOGY - WITH PHILOSOPHY OR WITH THE NATURAL SCIENCES?
}

\author{
BY PROFESSOR J. MACBRIDE STERRETT, \\ George Washington University.
}

You will thank me, I am sure, for an act of mercy. Instead of reading the whole of a very long address prepared for the occasion, I will make enough omissions from it, to leave half an hour for your discussion of the topic ${ }^{2}$ - of the topic, I say rather than of the address, because custom has sanctioned the President's address as taboo.

I am indebted to a happy accident for the topic. I need not tell you how many seductive themes offered themselves. . . . Then I reflected that ours was a society for psychology as well as for philosophy. So I went to the Library of Congress to look through some of the recent works on psychology. Somewhat to my surprise I found the works on experimental psychology classified under the heading of Physiology.

Thus under physiology are grouped experimental psychology, physiological chemistry and experimental pharmacology. That was the accident that suggested the topic which I wish to open for your discussion-i.e., the title of our society: The Southern Society for Philosophy and Psychology, or more specially the conjunction and between the two socii - philosophy and psychology. For the geographical part of our title is of minor import. In the North there are two separate societies - one for philosophy and one for psychology. Our provincial title, Southern, however, goes with a more generous and organic view. But it might be said that we meet together as one society only because we are too few and too scattered to be able to maintain two societies. I take the higher and more genial view -

'President's address before the Southern Society for Philosophy and Psychology, Baltimore, December, 1908.

2 The topic was discussed at Bome length by Professor J. G. Hume and Professor Ladd. (See Psychol,ogical, Buli,kTin, Feb., 1909). 
the old-fashioned view of the organic kinship between philosophy and psychology. Yes, we are sociæ - mother and daughter, philosophy and psychology.

In what $I$ have to say to-day I must not be taken as questioning for a moment, the desirableness of our union. Nothing could be further from $m y$ thought than to suggest a divorce in this domestic circle. It is quite possible however that the umbilical-cord-interpretation of the conjunction and will not be accepted by all the members of our own society. There is room for debate on the general subject. I need not remind you how philosophy suffered by the self-ex-matriation of many of her childrem. . . Is psychology, we may ask, one of these ingrates?

Is it to be a case of the cuckoo in the sparrow's nest? Or is it not, perchance, a case of the ugly duckling? - the arising of a new science - a beautiful daughter of the more beautiful mother? The new psychology has been coquetting with natural science, and philosophy has been looking askant at her wayward daughter. . . . In the near past the copula and has been stretched almost to the breaking point. . . . But now the rancor of the strife is past, and we are left with a purely academical question as to the proper affiliation of psychology - a question of the classification of the sciences. It may be a mere question of age.

"Crabbed age and youtb
Cannot live together."

Or there may be a more vital and organic cause. The very spirit and method of psychology may be much more akin to those of the natural sciences than to those of philosophy. Thus either party may raise the merely logical question as to the propriety of the conjunctive and. Are the two, philosophy and psychology, well paired? Is the vinculum of filiation valid, or has it become so unnatural that it should be broken? Does the conjunction and look well parading with a saint Cecilia on one arm and a madame Blavatsky on the other? Will a lion and a lamb consent to such a side-by-side conjunction? Will not the conjunction and be changed into the preposition within - the lamb within the lion? Then comes a question, which is the lion? 
President Stanley Hall answers that $p s y c h o l o g y$ is the lion. In his St. Louis address he says: "Our science is still like Milton's tawny lion." Till recently it has been philosophy that made the lion - claim of inclusiveness. For her part, I may say, she is now willing to give up the claim. Bishop Wilmer told a story of a colored groom coming back shortly after his wedding and asking to be unmarried. "Why', said the Bishop, "did you not take Dinah for better or for worse?" "Yah, yah," said Sambo, "but then she is a heap wusser than I took her for."

If not worse, psychology is certainly so very greatly changed as to make philosophy rather willing to have her go her own way. Meanwhile psychology has been putting forth hor claims of inclusiveness. . . . Here I need only to refer to the vivacious remarks of Professor Münsterberg on the expansionist policy of the new psychology. "Certainly," he says, "the good appetite of psychology has sometimes become voracity in our days, and she has begun to devour all the mental sciences history and social life, ethics and logic and finally alas! metaphysics." But this, he claims, is pathological and terms the disease psychologism. . . . There seems to be a glamor about the term psychology that to-day is ousting the term philosophy and evolution from their place. The press is pouring forth books and pamphlets and articles on the psychology of this, that and the other thing - the psychology of ants, antics and antiques; of cant, canticles and chanticleers and so on, from A to izzard. I would like to read you the titles of a hundred articles that I have picked out of the psychological journals. I will mention a few of them: The psychology of profanity, pain, pity; of laughing, landscapes and lies, and finally the psychology of literature, of science, of art, climaxing in the title of an article on the psychology of philosophy, or in a more recent one, on the psychology of psychology. Well! really, we older folk must gasp at this claim of psychology to be the scientia scientiarum. Frankly, we may admit that the new psychology has made good her claim to be a new science, and recognize to the full the enormous amount of good new work done by it. We may take it at its own pretensions and yet we may debate the question as 
to its place in the classification of the sciences, more specifically whether she ought to be divorced from philosophy. . . . It is a question of quid juris rather than of quid facti. Should psychology any longer affiliate with philosophy and the philosophical sciences, or should she be bidden a god-speed to conjunction with the long-wooed natural sciences-similia similibus?

At the joint meeting of the American Philosophical and the American Psychological Associations in 1905, held in the new Emerson Hall at Harvard University, this question of the proper affiliation of psychology was mooted. With delightful savoir faire, rather than with logical self-consistency, Professor Münsterberg, one of the strongest champions of psychology as a natural science, held that the housing of psychology in the new Emerson Hall of Philosophy settled the question, $i$. $e$, for Harvard University. Psychology had accepted the invitation and entered the hall as a co-habiter with philosophy. But that local and accidental arrangement did not touch the question of the quid juris of the affiliation. President Stanley Hall more logically held that psychology, as understood by both Professor Munsterberg and himself, should be recognized as one of the natural sciences and so be divorced from philosophy.

He said : "Psychology is a branch of natural science and can be fruitfully studied only in connection with the phenomena of the material world. Its business is to examine the physical and physiological conditions of mental states, and this it can do only by employing the methods of the natural sciences. As an empirical science it has nothing to do with metaphysics." Otherwise the tone of the discussion there was genial rather than logical. It was a house-warming party in the new hall of philosophy. The local quid facti was not to be seriously questioned, and so the prevailing sentiment was for the validity of the hereditary affiliation of psychology with philosophy.

But here is a later and a more significant incident. It was supposed to be a settled custom for these two large associations - the American Philosophical and the American Psychological Associations - to hold their annual meetings at the same time and place, and to arrange for joint meetings. Last year, how- 
ever, the American Psychological Association chose to hold its annual meeting in affiliation with the American Society of Naturalists in Chicago, rather than with the American Philosophical Association at Cornell. The long and rather vain coquetting of psychology with natural science here culminated in a throwing of herself as suitor into the arms of a very lukewarm beloved.

Our present meeting occurs in the very pandemonium of the sciences. Here our own society for philosophy and psychology has been partially absorbed into the American Psychological Association. Here too the great American Association for the Advancement of Science appears as a vast scientific trust - the Lion's den to which all other societies are making tracks. In fact we find that its section $H$ is given to anthropology and psychology. As far as psychology is a science, that I believe is its proper home. Philosophy could not get in even if it wished to do so. For, philosophy, whatever she may be, is not, and from her very nature, never can be, one of the sciences - in the modern narrow ses e of the very catholic term science. ...

A full discussion of this topic would involve the consideration of the nature, aim and methods and, of both philosophy and science and of the differentia which determine whether one branch of study is one of the philosophical disciplines, or one of the natural sciences.

Some of these questions are too well agreed upon to demand discussion before this audience. We all know the nature and the claims, or at least, the pretentions of philosophy, in its intensive sense of epistemology and ontology as held by catholic philosophy.

So too there is a general agreement as to the marks which assign any science to a place with the philosophical disciplines. The chief mark, I should say, is whether or not a science is normative.

We can also limit the discussion by our unanimous consent to affiliate rational psychology as represented chiefly in this country by Dr. Wm. T. Harris with philosophy. It is philosophical or nothing. The same is true in regard to the modern 
experimental form of the older introspective psychology as set forth by Ladd, Stout, Ward, Höffding, Baldwin, Calkins and others.

Without discussion we may accept philosophy at its well recognized position, not as one of the sciences; not as merely the unification of all the sciences, but as the science of the principles of all knowing and of the absolute reality back of all that with which the natural sciences deal. In her own eyes she walks a queen and we do not question her right, "We do it wrong, being so majestical." But as to psychology in its many new empirical forms we can say :

\section{"Thou comest in so questionable shape That I will speak to thee."}

Here I confess myself to be a mere inquirer, and I shall not be surprised to learn that every one of my opinions on the subject is false. I am perfectly sure, that from the standpoint of the new psychology, I am a back number, an old fossil of the defunct arm-chair psychology - one of those whom Dr. Stanley Hall has characterized as 'paranoiac minds' ' surcharged with paleo-atavistic traces,' 'sitting in prison' ' under the greatest delusion of the ideality of space.' I shall assume the standpoint of the philosopher, who is not technically acquainted with the new psychology, and base my remarks upon quotations from those who are specialists in the new science. . . . I certainly am not competent to give any but a very second-hand account of the present state of psychological literature. In the flux and flow of its development I cannot tell just what is an überwundener Stand-punkt, or what is just now the dominant view. Let me confess to a state of mental bewilderment, of what they call a 'functional or organismic feeling of non-orientation'; an attitude of 'unrelationalized psychic quality-content' when facing the literature and the laboratory work of the new psychology. ... It is all so unlike the old psychology!

Its literature bristles with the technical terms of physics, physiology and biology. I forbear giving you a list of its working terms that seem so unfamiliar to one of the old school. It speaks largely in an unfamiliar tongue and works at largely unfamiliar problems. 
Ribot says: "The new psychology differs from the old in its spirit - it is not metaphysical; in its end - it studies only phenomena ; in its procedure (or method) it borrows, as much as possible, from the physical sciences." Professor Angell says : "The tendencies which have contributed to render psychology so largely independent of philosophy are for the most part identical with those which have brought it under the guiding influence of biology." ...

We note too the large space occupied in its literature by a sort of an internecine warfare, a mutually destructive criticism of its different forms, so that one might be tempted to follow Hume's method of dealing with the various forms of religion, setting them, like so many Kilkenny cats, at an internecine struggle till nothing is left of them but tails. . . One quotation from Professor 'Titchener must suffice: "I have," he says, "little sympathy or patience with these experimentalists who would build up an experimental psychology out of psychophysics and logic; who throw stimuli into the organism and take reactions out, and then, from change in the nature of the reactions, infer the fact of a change in consciousness. Why in the world should one argue and infer, when consciousness itself is there, always there, waiting to be interrogated. This is but a penny-in-the-slot sort of science. Compared with introspective psychology, it is quick, it is easy, it is often showy." . . .

Münsterberg says, what no philosopher would dare to say: "It seems to me that the new discoveries in modern psychology have often an existence of only four months." We might say then that it seems to be as near to being a science as pragmatism is to being a philosophy. It may weary you - if a quotation from Professor James could ever weary any one - to have repeated the closing words of his Psychology: "It is indeed strange to hear people talk triumphantly of the new psychology and write histories of psychology, when into the real elements and forces which the word covers, not the first glimpse of clear insight exists. A string of raw facts: a little gossip and wrangle about opinions; a little classification and generalization, but not a single law in the sense in which physics shows us laws. This is no science; only the hope of a science. At 
present psychology is in the condition of physics before Galileo and the laws of motion, of chemistry, before Lavoisier and the notion that mass is preserved in all reactions." . . .

Dr. Stanley Hall, who seems to be a sort of a Thersites in the camp, in both his Harvard and St. Louis addresses is garrulously querulous, almost senescently adolescent in his declamation against metaphysics in the new psychology. "The present glowing twilight of the new psychology," he says, "is that of the dawn, not of the evening " But even in its present early form of adolescence it is ever lapsing into senescent reminiscence of the metaphysical problems of the old psychology. ... And so we find this constant accusation made against every form of psychology. All accuse each other of being metaphysicians. L'ennemi c'est la metaphysique.

.. I omit, as I have said, rational psychology and all forms of what I choose to call psyche-psychology. All forms where at least one's empirical self or soul or active consciousness is the basal fact for study ; all forms where the concept of personality stands as the ideal and the problem and the inspiration of the work - whatever method may be used such forms of psyche-psychology rightly, by common consent, should be affiliated with the philosophical disciplines.

Affiliating all forms of psyche-psychology with philosophy, we may turn to forms which, with Lange, "calmly assume a psychology without a soul" ; that at least reduce psyche to a nonactive epiphenomenon of physical phenomena; where the interest is chiefly with the non-psychical as the material from which a non-psychical, psychical automaton may be constructed - that is, to all forms that may be included under the term scientific psychology, in the rigorous and narrow sense of the term scientific.

But here let it be said that there are some forms of structural psychology which belong to psyche-psychology and there are others which belong to this latter group.

The same may be said as to some forms of functional psychology. That is, the ideal and problem may be such as to classify some forms of functional psychology with psyche-psychology, while there are others where it is little more than a 
branch of biology, and the others where it is a form of psychophysics with the accent upon physics. Thus with Angell, the problem of the functionalist is one of determining just how mind participates in accomodatory reactions, thus putting the accent upon psyche.

The term the new psychology is too broad being inclusive, as it is, of modern forms of the psyche-psychology. If we can submit to the rigorous but defective modern definition of science, we may classify them as (I) the old or unscientific psyche-psychology, (2) the new or scicntific hypo-psychepsychology. But both of these may be experimental. For the experimental method, which is claimed as the distinctive mark of scientific psychology, is also used by the other school. The only question is, whether these experimental methods are analogous to, or identical with those of physics and physiology and whether or not they are applied to the same subject-matter.

We find both structural and functional psychologists to be chary and wary of psychc. They fear its recrudescence, just as biologists fear any recrudescence of vitalism. They fear the introduction of any teleological explanation, or any recurrence of any form of the old faculty-psychology, where faculties, as organic manifestations of a substantial mind were made explanatory of mental processes and results. They hold that, historically and scientifically psyche has been a vanishing factor.

Dr. Stanley Hall regrets the lingering hold that the questions raised by the old psychology has even yet upon scientific psychologists.

His attitude toward all questions raised by the other older psychology is quite like that of Callicles in Plato's Gorgias (485) one of pity and contempt, except as a training stage for the young. Thus, he says: "For many, if not for most, a touch of it, but not too much of it, is perhaps, a part of the complex initiation of youth into its world; but the severer types of this discipline seems more suited to senéscent than to adolescent men and races." To be scientific then, all forms of psychology must banish an active self-manifesting and self-realizing psyche. Hamlet must be left out of the play. 
As to structural analytic or idea-psychology. This form of psychology is strictly analytical of psychoses, states of consciousness, ideas, as mere phenomena, abstracted from any active psyche. It is after the elements in any psychosis and their quantity, so as to construct a psychic-automaton. It is held to be scientifically irrelevant to ask whose psychosis one is analyzing. Ideas are atoms, instead of being experienced functionings of a self. Explanation is sought in non-psychic terms by reference to physiological distinctions. It treats its analyzed elements as real parts, whose mechanical composition is the mental life. Whether there is any personal mind back of the stream of ideas, says Titchener, is a question that cannot be raised in psychology.

Functional psychology is a bit less abstract. It has at least processes instead of cross-sections of consciousness, or rather of the psycho-physical organism in its reaction to external environment. At first it looks like a bit of teleological self-activity being introduced into the psychological automaton. But this is a mistake. The reactions, the controls are not within the organism, but from the environment. Description, it is true, is in terms of value. Function is identified with use.

But when we ask, useful for whom, we find only the impersonal psycho-physical organism. That is its basal fact, not a self-active or conscious self. Hence its concern is with the sensori-motor processes of this organism, body-reactions and attitudes, whose processes and functions are biological rather than psychological phenomena. Activity in relation to environment becomes mechanical physics. Reactions are considered as essentially motor processes. They are mechanical functions, not activities of a functioner. In this psycho-physical organism purely physiological functions are recognized but not any purely psychical functions. There is a body, an organism but there is no psyche to function. Hence functional psychology is logically a branch of biology. Professor Kirkpatrick suggests that functional psychology be broadened to include the fuctioning of all organisms, whether conscious or unconscious, and suggests the term organosis.

Genetic psychology seems to take a further step toward a concrete form of psychology. Lloyd Morgan says that it takes 
its place between biology and such normative sciences as ethics and æsthetics, with their doctrine of worth for the ideal life of man. "The starting point is in close touch with purely biological reactions and the goal is our systems of knowledge and our ethical conceptions." It is functional, teleological, evolutionary and synthetic. It puts the control system, a sort of effective consciousness, within the purely organic activities in their reaction to environment. That is, it uses the conception of 'purely psychologically-guided or intelligent behaviour, as distinguished from reactions which are purely automatic.' Thus we may have a genetic psychology in place of the genetic biology of functional psychology, and thus a form of psychology which should be affiliated with philosophy, whether in the form of individual, social or race psychology. As critical of structural psychology, of its barren, abstract, cross-section-piece-ofconsciousness mythology, and as carrying forward the more concrete view of functional psychology, we may believe with Professor Baldwin that genetic psychology is fast coming to its rights, and that it has a great future before it. I say we may have such a form of genetic psychology. But I am compelled to say zue do have forms of it that are to be classed with the purely evolutionary physical sciences. For disguise, despise, abjure metaphysics, as we may, we do not and cannot find any form of psychology which does not presuppose and rest upon both an epistemology and a metaphysic.

Professor Baldwin says that the two principles which distinguish the new psychology are its adherence to the principles of naturalism and positivism, both as to spirit and method.

But Baldwin pronouncedly divorces both these terms naturalism and positivism - from the metaphysics that often go with them. He says, that the platform on which he describes the development of modern psychology is "that of cognitive and reflective self-consciousness of such a sort as that which the individual has attained when he thinks of his inner life as a more or less consistent unity, passing through a continuous and developing experience: a self different from things and also different from other selves : yet finding its experience and exercising its functions in closest touch with both." Again, Bald- 
win says: "What is it that feels and knows? It can only be a unitary subjectivity, additional to the unity of sensory content, $i$. $e$, the synthetic activity which reduces the many to the one in each and all the stages of mental growth." It is, indeed, only on the theory of a self-active subject that any truly genetic psychology can be had.

With such a conception of a self, a synthesizer, a functioner, a self-realizing activity, we may use all the methods of naturalism and positivism; all the methods of modern experimental psychology - structural, functional, genetic ; all laboratory, all psycho-physical and psycho-metrical methods. What I have termed psyche-psychology welcomes and uses all the results of all the methods of both naturalism and positivism, and only objects where methodology is bottomed on an ontology, naturalistic and positivistic. Through all these results there is an enrichment of our conception of the psyche that is fundamental in any logical form of psychology. As long as psychic phenomena are not analyzed into non-psychical factors, so long every analysis of the constant activities of the complex psychophysical organism with the emphasis upon the physical, will be useful material for the psyche-psychologist. All grain that comes to his mill are his grists.

But where we have 'structure' or 'idea' without a 'whose,' or function without a functioner; or genesis without a generator; or a measure without a measurer - in a word, to be both epistemological and ontological, where we have mere phenomena or epiphenomena in a numerical and quantitative order and causal relation - there we have a form of psychology that should be affiliated with the natural sciences. I have a profound admiration and respect for the large amount of fine original work done by all the workers in scientific psychology. But I confess that a very large part of their work as well as their method seems to me to be unpsychological. They are studying something, but it is not consciousness or psyche, and psychology is the science descriptive of consciousness. That should be the root of the matter, whereas, with them, it is at most a convenient general abstract term to hold together a lot of abstractions, from the activity of the concrete psyche. I 
have no obnoxious religious or philosophical criticism to make on the scientific study of this subject-less, ego-less, psyche-less, phenomenal matter of the new psychology. But the question that I raise is as to the logical affiliation of this scientific work with the philosophical disciplines. Leaving all forms of psychepsychology whether new or old, whether empirical, inductive experimental, descriptive, analytic or not - leaving all these forms affiliated with philosophy, we ask where is scicntific psychology to be placed? Under this come some forms of structural and functional and genetic psychology. But more distinctively scientific are psychological psychology and psychophysics.

We find many of the exponents of all these forms of psychology strenuously denying affiliation not only with philosophy, but also with the philosophical disciplines. In spirit, aim, method and, largely, in subject-matter they are not merely analogous to, but identical with those of the natural sciences. We hold that these forms of psychology should be affiliated with the natural sciences for the following reasons: It is the wish of their exponents. This wish comes from sympathy and congeniality with the spirit, aims and methods of the natural sciences. . . These methods are applicable not to qualitative, intensive states, of the internal sense, but only to sensuous spatial pinenomena. Kant made a mistake in his first edition which he corrected in his second edition which the neo-Kantians and all positivists have resolutely enforced. That is, the application of the categories of physical science to phenomena of 'the internal sense' is denied in the second edition and confined to only external, spatial phenomena. Hence Kant holds, as logically do his neo-disciples, that psychology can never become " a natural science of the soul or even an experimental doctrine in regard to it."

It is notable too that in his first edition he treats empirical psychology as a stranger within the philosophical fold, though then holding that the categories were applicable to phenomena of the inner sense. That is, granting that there could be a science of the data of the inner sense, it would be merely empirical and have no philosophical interest. In the second edi- 
tion he denied the possibility of an empirical science of the data of the inner sense and hence of any science of the psyche. The categories or the analogies of experience, as the principles of science, are not applicable to the phenomena of the inner sense, but only to those of the outer sense, $i$. e., spatial phenomena. We have, Kant then declares, "from things without us, the whole material of our knowledge even of our inner sense" (Pref., XL.). And in his incomprehensible Refutation of idealism he says that "our inner experience is itself only possible mediately and through external experience."

In a word, he pointed to physiology and anthropology as the only forms in which we can have a scientific psychology - the way that Lange and the neo-Kantians and positivists resolutely enforce. It is this regnant phenomenalism in psychology that accounts for the consistent refusal to take as a factor, a psyche, self, or consciousness, because that is not a sensuous phenomenon. The term psychc has been so greatly implicated with religious ideas that there has come a preference for the term consciousness or conscious subject. But this should not obscure its ancient and perduring usage as a philosophical term. We need not quarrel about the term. It is the fact of a permanent, substantial, self-realizing ego that is denied in scientific psychology. It abides by Hume's contention - "Show me the impresson from which this idea of self arises." . . Identity and continuity are here, like the causal nexus, but a fiction of the mind, which itself is a fiction. Certainly positivism and atomism dominate the work in structural psychology. Munsterberg says : "From the standpoint of psychology consciousness is only an abstraction from the totality of conscious facts. Consciousness does not do anything, it is only the empty place for the manifoldness of psychic facts." Thus denuded of all concreteness and activity, psyche is but the verbal ghost of the Gheist regnant in the older psychology. It is a general term, a mere flatus vocis, enjoying perpetual otium cum dignitate in the work of the phenomalistic positivists. But the fact is that conscious states are abstractions. Consciousness itself in an abstraction. The concrete given reality is self-consciousness, with states, etc. States of consciousness are really states of a con- 
scious being, self, psyche. . . Professor Bush speaks of consciousness as 'a diaphanous medium through which, on occasions, objects are united,' or as ' the faint rumor left behind by the disappearing soul upon the air of philosophy.'

Professor James discussing Does Consciousness Exist? ${ }^{2}$ says (J. P., 147): "For twenty years I have mistrusted consciousness as an entity; for seven or eight years past I have suggested its non-existence to my students. It seems to me that the hour is ripe for it to be openly and universally discarded."

As to the 'Ich denke' that 'muss alle meine Vorstellungen begleiten Können,' the merely logical permanent self of $\mathrm{Kant}$. Professor James, who always dares to say very daring things in a very brilliant way, finds it to be but a careless name for the stream of breathing. He says : " "The 'I think' which Kant said must be able to accompany all my objects is the 'I breathe' which actually does accompany them. There are other internal facts besides my breathing (intercephalgic muscular adjustments, etc.) and these increase the assets of consciousness but breath, which was ever the original of 'spirit,' breath, moving outwards, between the glottis and the nortrils, is, I am persuaded, the essence out of which philosophers have constructed the entity known to them as consciousness. That entity is fictitious while thoughts in the concrete are fully real. But thoughts in the concrete are made of the same stuff as things are.". . .

The older psychology is both descriptive and normative. As normative, it affiliates with philosophy as do the other normative sciences. But scientific psychology is not a normative science. The very terms norm, ideal, teleology are deepdyed red rags of metaphysical popery. Mechanism, mechanical causality is the regnant concept of scientific psychology. It does not seek to describe concrete, active consciousness, but to find the causal tie between the parallel physiological processes and the abstract mental atoms so as to construct a psychical automaton. It denies any causal tie between these psychical atoms and also between them and their physiological and

'Jour. Phil., Psy. and Scientific Methods, I., p. 477.

'Jour. Phil., Psy. and Scientific Methods, I., p. 49 I. 
physical conditions. Here I need to do no more than refer to Professor Münsterberg's popular exposition of this in his Psychology and Life, where he allows that the psychical automaton thus constructed by scientific psychology is far from being a description of the real living self. From his statement it appears to be but a caricature rather than a character-sketch of the real concrete psyche - a merely kinematographic simulacrum of psyche.

As to the protesting real psyche that he hands over to history, ethics and religion, though he calls it 'will,' he speaks of it in such negative terms, as 'non-psychic,' 'non-personal' as to make it seem a nondescript nonentity - sans culotte - sans tous les choses. It is unnecessary for me to repeat what he feels called upon to say ad populum about the limitations of the psycho-construct of scientific psychology - at the expense of affording pleasure to its enemies - "It is not at all an expression of reality, but a complicated transformation of it, . . an abstract psychical antomaton." He adds, "Every fiber in us revolts and every value in our real life rejects such a construction.". . .

Scientific psychology aims to predict or, to vary the phrase, to explain. And explanation, to be scientific, must always be causal, and so, in non-psychic terms and of non-psychic phenomena.

It is a case of mechanism versus the teleology regnant in all the normative philosophical disciplines. Scientific psychology explains by giving the invariable set of antecedent physical facts. The causal nexus is found between the physical facts, but they do not, and, on their epistemological theory, they cannot allow any causal nexus between the parallel psychic phenomena - nor indeed between the two parallel set of phenomena. It is impossible to see how they can get any psychical automaton constructed. On the other hand we may note that since the days of Plato and Aristotle, ultimate explanation looks not backward for explanation, but forward to the function or final cause as the real explanation. Respice finem.

The only psyche in the work is that of the psychologists, and it is reduced to a mere spectator of objective phenomena with 
hypothetical parallel concomitant psychoses - the inert, causeless and uncaused accompaniments of certain transformations of matter and energy. Any psychologist may well fear for his reputation for modernity if he upholds a psyche. That must be religiously disavowed. In psycho-physics the psyche is only permitted because of its union with physics. Psyche alone - well, that is snubbed and bowed out, or only taken in at the back door and told to keep quiet, as quiet it must keep, as it can make no acoustic utterance. This utterance is, after all, the real thing and so psychology is a form of physics. It is a science, but not a science of the soul. It would not care to be styled a science of no-soul, though even functional psychology comes near this in its treatment of a body-soul, psycho-physical organism. Here, as Dewey says, "the distinction between the physical and the spiritual is one of interpretation of function rather than of kind." That is, the distinction is merely mental, functional distinctions within one organism. The body may as well be said to have a soul as the soul a body. It is all one organism in time and space conditions. There is no known soul. We have a soul-idea, which is obnoxiously intrusive in all scientific study. But it corresponds to no reality. We can trace its psychological genesis out of such stuff as dreams are made of. It is granted that this concept will survive as long as men are religious, or as long as they ask the inane questions that Rational Psychology asks.

It may occur to one to ask by whom or through whom was the soul-idea conceived, if not by a psychical conceiver and his confreres. Or is it a construct of impersonal atoms in their causal nexus through all ages, especially the early ages? But ages of whom or for whom? There are no ages for a what. Through the ages for psyche, psyche has constructed the psycheidea, as implicative, as revelations of her real self. A construct

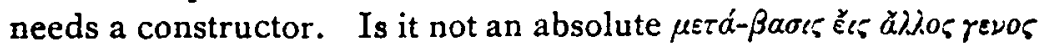
to pass to a psychical construct from a physical order? At least if the psyche-idea is a construct of physical antecedents, why is it not just as valid as the concept of causality, which must have been generated by the same sort of physical antecedents? One here very naturally raises the question as to the propriety of keep- 
ing the name psychology. Karl Lange, who gives the epistemological basis of this non-ontological science, himself raised the question. In arguing against the hypothesis of a soul he says : "But does not psychology, then, mean the doctrine of the soul? How then is a science conceivable which leaves it doubtful whether it has any object at all? Well, here we have a charming example of the confusion of a name and a thing. We have a traditional name for a considerable, but by no means accurately defined group of phenomena. This name has come down from a time when the present requirements of strict science were unknown. Shall we reject the name because the object of the science has been changed? That were unpractical pedantry. Just calmly assume a psychology without a soul and the name will still be found useful."

My friend, Rev. Dr. Frank Sewall, of Washington, suggests the term hypo-psychics as a better name for the new science.

Later on we find Lange demanding that all psychological definitions be replaced by physiological ones, thus leaving psychical phenomena to stand only as provisional indices of physiological ones. But all such efforts to reduce psychology to physiology, in order to have a scientific psychology is to virtually abolish psychology in order to make it into a science. They proceed on the theory that science obtains only where the relation of cause and effect can be reduced to a relation of identity or continuity, so that quantitative equations become possible. This can only be in the material sphere. Only where we have quantitative states can there be science. Therefore parallel quantitative states, physiological manifestations, are to be substituted for the psychical ones to get quantitative determinations carrying out a strict causal connection, in order to have a scientific psychology. Lange set the example of decrying the inane method of introspection in favor of external observations of a physiological sort. Thus contempt of introspection has been a flaunting note of the new school until we find a noteworthy exception in Titchener who, deprecates "That neglect of introspective control in psychology, which has been the besetting sin of many whose direct interest lies in psycho-physics," insisting upon introspective analysis as the method of psychology. 
"The course of experimental psychology he says in recent years has been away from simple psycho-physical determinations and towards introspective analysis." A philosopher would not dare to characterize some of the laboratory work in psychophysics as Professor Titchener does - as ' a penny-in-the-slot sort of science.' " Tables and curves of reaction etc.," he says, "are useful, and the psychological laboratory is the place for them. But there is no reason why one should gain psychological credit for them - still less for erecting a speculative psychology on their foundation. This mode of psychologizing is inherently as vicious as any of the constructive modes of the older psychology."

But most of the work in the new science is carried on without introspection, the only door into the specific subject-matter of psychology. Thus Cattell says: "Most of the work done by myself and others in my laboratory is nearly as independent of introspection as work in physics or zoology."

But all this is not psychology and indeed no part of psychology, unless it be held as merely supplemental to that which treats of the processes of the self-activity revealed only by introspection - itself a form of self-activity. If the old psychology be termed metaphysics, the ncw may well be termed hypopsychics. ...

We have noted the reason Münsterberg gives for this abstract construction and how strenuously he affirms that it by no means resembles the real self, the actual psyche of himself or any of his fellows. . . . We confess to being unable to appreciate the end to be served by such a psychic-construct. In later chapters he disclaims any use for it as applied to pedagogy, art, history, ethics or religion.

It is just here - granting a possible limited use for their psychological automaton - here where it logically calls halt that we would plead for a further function of psychology in describing the teleological processes of real life, in ethics, art, history and religion. That is, we plead for the place of another form of psychology - that of the old psychology in modern form - for psyche-psychology.

This pleads for the subject-matter revealed only by introspec- 
tion - the self-activity of a knowing, willing, feeling self, that no eye nor microscope can ever see, and that no mechanical causality can order into a mechanical science. Kant's paralogisms were only aimed against such a natural science of the self, without whose synthetic self-activity there would be neither subject-matter or form for natural science. The self for whom these are objects cannot itself be an object like them. The whole of his Critiquc, which gives the principles of science, is itself a refutation of his paralogisms so far as they are directed against the self-consciousness that is the source of all the categories. The source of the categories cannot be subjected to them. The center cannot be put as a point in its own selfgenerated circumference, because the source - the generating center - is more real than its own phenomenal creations.

The old psychology only pleads for the recognition of this knowing self, that knows itself, not as it knows its objects, but by an act of pure apperception or self-consciousness - that knows itself in knowing objects and only knows these in knowing itself; that knows its own knowing in its work of gripping all its objects into ologies, from geology to theology. Such a psychology may be ridiculed as being an art rather than a science. But that only reveals the limitations of science. . . .

One illustration may suffice. We go back to one of the oldest psychologists of the psyche-psychology, Socrates. Münsterberg himself refers to how scientific psychology would explain the causes of Socrates turning a deaf ear to the plan of his friends for him to escape from prison and death. "Socrates remained in prison because his knee muscles were contracted in a sitting position and not working to effect his escape, and these muscle-processes took place because certain psychophysical ideas, emotions and volitions, all composed of elementary sensations, occurred in his brain, and that they, again, were the effects of all the causes which sense stimulation and dispositions, associations, produced in that organism." But the fact is that Socrates remained in prison because his inner monitor, deamon, conscience, sense of duty, forbade him to be disloyal to his mother, the state. Socrates is himself criticizing this very old hypothesis that has been recrudesced in the new 
scientific psychology. The whole passage in the Phaedo is worth many repetitions. I give it in part. Socrates was holding the principle that psyche is sclf-active and the cause of action. The natural science teacher tells me, he says, " that I sit here because my body is made up of bones and muscles, which are moved by contraction and relaxation, and this is why I am sitting in a curved posture." But the true cause Socrates replies is "that I have thought it better to remain here and undergo my sentence; for I am inclined to think that the muscles and bones of mine would have gone off to Megara or Beotia by the dog of Egypt - they would, if they had been guided only by their own ideas of what was best, and if I had not chosen as the better and nobler part, instead of playing truant, and running away, to undergo any punishment which the state inflicts." With this illustration we rest our contention for another form - for the form of the old psyche-psychology, which seeks to understand the self-activity; the self-revealing and self-realizing character of psyche in and through the personality that works out the attainments of the truly-human in art, history, ethics and religion and philosophy - in both the objective institutions and in the creations of the ideals that lead ever upward and onward. With the acknowledgment of this as the primary function of psychology there need be no undervaluing of the work of scientific psychology in its very limited function of giving us formula of the relatively mechanical aspects of our mental life, by means of which to calculate the future actions of our fellow men. Psyche-psychology only asks that the new science may not pursue its work with a sort of persuasion that there is no inner self-active being at its heart. It asks that a non-spatial, non-sensuous psyche be not regarded as an obnoxious intruder, but as something more real and more substantial than all its physiological and physical conditions.

Doing this it may then go on with its own special lines of study of these conditioning environmental stimuli - these enthralling means of self-liberation-conditions of body, age, sex, race and clime. It would then be a most valuable part of psychology - the science which describes and explains the evolu- 
tion - the self-realizing and ripening of the soul, self, personality, or spirit that forms the central subject-matter of psychology. It would thus supplement and enrich the work of the old unscientific or hyper-scientific psychology.

I believe that if a vote of the workers in scientific psychology could be taken, the majority would be in favor of the affiliation of the new science with the natural sciences. But philosophy would here hold with Mathew Arnold that " numbers," the majority, is bad. Philosophy like Plato's God is not envious. Like the New Jerusalem which is above, she is the mother of us all, and rejoices at the adolescence of each one of her offspring. For psychology she has a special interest and a mother's yearning to keep it at home, when she realizes that the time has come for it to go out as an independent science. In its new form she needs it, indeed, but only as she needs all other sciences.

Philosophy is burdened with the consciousness of the chaos of experience which she was born to turn into a cosmos. She needs the material of all the sciences. She needs specific questions raised. And there is no science which raises so many profound questions as psychology raises. Indeed it may be shown that all philosophical problems emerge by a psychological necessity from the study of psychology.

In this way it should continue to be the special propædeutic to philosophy. No one ignorant of psychology can enter philosophy - however much Plato may say about mathematics. It is psychology that especially gives philosophy the Antean touch with mother Earth that she may rise with earth to heaven. Psychology, instead of being the cuckoo in the sparrow's nest may, even in her scientific form, be the ugly duckling that at maturity leaves the puddle to join her sister philosophical disciplines in the empyrean blue. Psychology will have to be a "heap wusser" before philosophy will wish to be unmarried from her. 